\title{
Identification of Cytological Features Distinguishing Mucosa-Associated Lymphoid Tissue Lymphoma from Reactive Lymphoid Proliferation Using Thyroid Liquid-Based Cytology
}

\author{
Ayana Suzuki $^{a}$ Mitsuyoshi Hirokawa ${ }^{b}$ Aki Ito ${ }^{a}$ Nami Takada ${ }^{a}$ \\ Miyoko Higuchi $^{a}$ Toshitetsu Hayashi ${ }^{b}$ Seiji Kumab ${ }^{b}$ Akira Miyauchic

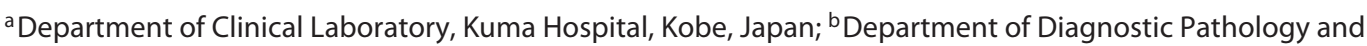 \\ Cytology, Kuma Hospital, Kobe, Japan; ' Department of Surgery, Kuma Hospital, Kobe, Japan
}

\section{Keywords}

Thyroid - Lymphoma - Mucosa-associated lymphoid tissue · Liquid-based cytology · Hashimoto thyroiditis

\section{Abstract \\ Objective: To identify cytological differences between mu- cosa-associated lymphoid tissue lymphoma (MALT-L) and nonneoplastic lymphocytes using thyroid liquid-based cy- tology (LBC). Study Design: We observed LBC and conven- tional specimens from 35 MALT-L cases, 3 diffuse large B-cell cell lymphoma (DLBCL) cases, and 44 prominent nonneo- plastic lymphocytic infiltration cases. Results: In MALT-L cases, the incidence of lymphoglandular bodies in the LBC specimens was lower than that in the conventional speci- mens ( $p<0.001)$. Moreover, the nuclear sizes in LBC speci- mens were larger than those in conventional specimens. In $62.9 \%$ of the MALT-L and all DLBCL specimens, large nuclei were present in $>10 \%$ of the lymphoid cells in LBC speci- mens. Two cases with prominent nonneoplastic lymphocyt- ic infiltration also exhibited these findings. In LBC specimens, swollen naked nuclei with less punctate chromatin patterns}

and thin nuclear margins were observed in $92.1 \%$ of lymphoma and $20.5 \%$ of prominent nonneoplastic lymphocytic infiltration. Elongated nuclei were significantly more apparent in thyroid lymphoma than in prominent nonneoplastic lymphocytic infiltration ( $p<0.001)$, with a significantly higher incidence in LBC specimens than in conventional specimens $(p<0.001)$. Conclusions: Lymphoglandular bodies are not reliable markers for lymphoma diagnosis using LBC specimens. Large, swollen naked, and elongated nuclei are useful in distinguishing thyroid lymphoma from nonneoplastic lymphocytes in LBC specimens.

(C) 2018 The Author(s)

Published by S. Karger AG, Basel

\section{Introduction}

Liquid-based cytology (LBC) has recently become increasingly popular for thyroid aspirates [1]. LBC specimens have been used to identify some diagnostic clues for papillary thyroid carcinoma (PTC), nodular goiter, and follicular neoplasm, such as convoluted nuclei, intercellular spaces, cytoplasmic changes, and membranous ma-

\begin{tabular}{ll}
\hline KARGER & $\begin{array}{l}\text { Ka 2018 The Author(s) } \\
\text { Published by S. Karger AG, Basell }\end{array}$ \\
Open access \\
E-Mail karger@karger.com & This article is licensed under the Creative Commons Attribution- \\
www.karger.com/acy & $\begin{array}{l}\text { NonCommercial-NoDerivatives 4.0 International License (CC BY- } \\
\text { NC-ND) (http://www.karger.com/Services/OpenAccessLicense). } \\
\text { Usage and distribution for commercial purposes as well as any dis- } \\
\text { tribution of modified material requires written permission. }\end{array}$
\end{tabular}

Correspondence to: Ms. Ayana Suzuki

Department of Clinical Laboratory, Kuma Hospital

8-2-35, Shimoyamate-dori, Chuo-ku

Kobe, Hyogo 650-0011 (Japan)

E-Mail suzuki01@ kuma-h.or.jp 
terial $[2,3]$. However, cytological findings from conventional and LBC specimens have shown some differences [4-6].

Primary thyroid lymphomas are usually non-Hodgkin B-cell lymphomas and reveal preexisting Hashimoto thyroiditis $[7,8]$. There are two types of lesions: the aggressive, diffuse large B-cell cell lymphoma (DLBCL) and the indolent, mucosa-associated lymphoid tissue lymphoma (MALT-L) [9]. Cytological diagnosis of DLBCL is not difficult [10]. However, MALT-L is frequently confused with Hashimoto thyroiditis associated with prominent lymphoid proliferation [11-14]. Thus far, the cytological findings for both have been described only in conventional specimens. To the best of our knowledge, there are no reports describing the cytological findings of primary thyroid lymphomas using LBC specimens. Therefore, in this study, we aimed to clarify the cytological differences between MALT-L and reactive lymphoid proliferation using thyroid LBC specimens.

\section{Materials and Methods}

We reviewed the pathology report database of 70 MALT-L cases, 13 DLBCL cases, 61 Hashimoto thyroiditis cases with prominent lymphoid proliferation, and 148 PTC cases with prominent lymphocytic infiltration. All of the patients were operated on at the Kuma Hospital from January 2013 to November 2016. The diagnosis of MALT-L was based on the following criteria: (1) diffuse proliferation of medium-sized CD20-positive lymphoid cells, (2) packing or lymphoepithelial lesion composed of CD20-positive lymphoid cells and follicular cells, (3) follicular colonization confirmed by structural alterations in the meshwork of CD23-positive follicular dendritic cells, and (4) at least one of restricted light chain $(\kappa / \lambda$ ratio $>3$ or $<0.33)$ by flow cytometry, chromosomal abnormality by G-banding, or immunoglobulin heavy chain gene rearrangements [15]. The diagnosis of DLBCL was based on diffuse proliferation of large CD20-positive lymphoid cells. Cases with none of the above findings were diagnosed as Hashimoto thyroiditis with prominent lymphoid proliferation. Data from $35 \mathrm{pa}-$ tients with MALT-L, 3 with DLBCL, 19 with PTC with prominent lymphocytic infiltration, and 25 with Hashimoto thyroiditis with prominent lymphoid proliferation who underwent preoperative fine needle aspiration cytology and had both conventional and LBC specimens prepared were included. Conventional specimens were prepared by expressing the aspirated material from the needle onto slide glasses and compressing on a second slide, followed by immediate fixation using a cytological fixative. Subsequently, the needles were rinsed gently with $6 \mathrm{~mL}$ of CytoRich ${ }^{\mathrm{TM}} \mathrm{RED}$ collection fluid (Becton, Dickinson, Franklin Lakes, NJ, USA). LBC specimens were prepared by the CytoRich ${ }^{\mathrm{TM}}$ hand method (Becton, Dickinson). Both types of specimens were simultaneously stained using the Papanicolaou method.

We observed conventional and LBC specimens under $\times 200$ magnification. We examined the following cytological aspects: colloid material, multinucleated giant cells, lymphoglandular

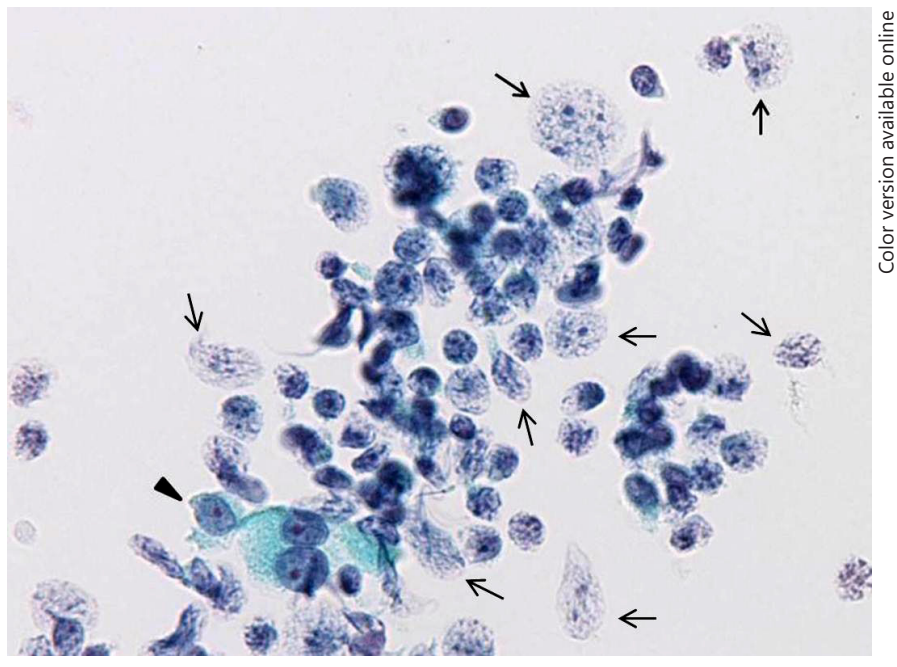

Fig. 1. Mucosa-associated lymphoid tissue lymphoma. The nuclei of lymphoma cells (arrows) are swollen and naked. The chromatin pattern is less punctate, and the nuclear margin is thinner. The chromatin is smashed, and nuclear margin is discontinuous. Follicular cells (arrowhead) have distinct cytoplasm, and the nuclei are not degenerative (LBC). Papanicolaou stain. $\times 400$.

bodies, oxyphilic cell clusters, and lymphoid cells. The presence of oxyphilic cell clusters was determined when more than 4 clusters composed of oxyphilic cells were observed on 1 slide. Lymphoid cells included both lymphoma cells and nonneoplastic lymphocytes. We defined nuclei with a size $>10 \mu \mathrm{m}$ in the major axis as large nuclei. To measure the nuclear size, we used WinROOF image processing software for Windows (Mitani, Tokyo, Japan), and at least 100 lymphoid cells were measured in each case. Swollen naked nuclei were defined as enlarged, naked nuclei with less punctate chromatin patterns and thin nuclear margins. We assessed the statistical significance of the data using Fisher's exact probability test and the independent-sample $t$ test. $p<0.05$ was considered statistically significant.

\section{Results}

\section{Background Components}

In LBC specimens, colloid material and oxyphilic cell clusters were seen in 22.9 and $42.9 \%$ of MALT-L cases, respectively (Table 1). This incidence was lower than that in Hashimoto thyroiditis with prominent lymphoid proliferation. The differences were statistically significant $(p<0.05, p<0.001)$. In conventional specimens, the frequency of lymphoglandular bodies was significantly higher in MALT-L (68.6\%) than in Hashimoto thyroiditis with prominent lymphoid proliferation $(20.0 \%)(p<$ 0.001 ). Oxyphilic cell clusters were seen in $20.0 \%$ of 
Table 1. Findings for background components in thyroid lymphoma and Hashimoto thyroiditis with prominent lymphoid proliferation

\begin{tabular}{lllll}
\hline & & MALT-L (35) & DLBCL (3) & HT-PTP (25) \\
\hline Colloid material & LBC-S & $22.9 \%(8)$ & $0 \%(0)$ & $56.0 \%(14)^{*}$ \\
& C-S & $20.0 \%(7)$ & $33.3 \%(1)$ & $32.0 \%(8)$ \\
Lymphoglandular bodies & LBC-S & $11.4 \%(4)^{\dagger \dagger \dagger}$ & $0 \%(0)$ & $20.0 \%(5)$ \\
& C-S & $68.6 \%(24)$ & $66.7 \%(2)$ & $20.0 \%(5)^{* * *}$ \\
Multinucleated giant cells & LBC-S & $14.3 \%(5)$ & $0 \%(0)$ & $24.0 \%(6)$ \\
& C-S & $2.9 \%(1)$ & $0 \%(0)$ & $20.0 \%(5)$ \\
Oxyphilic cell clusters & LBC-S & $42.9 \%(15)$ & $0 \%(0)$ & $92.0 \%(23)^{* * *}$ \\
& C-S & $20.0 \%(7)$ & $0 \%(0)$ & $76.0 \%(19)^{* * *}$ \\
\hline
\end{tabular}

MALT-L, mucosa-associated lymphoid tissue lymphoma; DLBCL, diffuse large B-cell cell lymphoma; HT-PTP, Hashimoto thyroiditis with prominent lymphoid proliferation; LBC-S, liquid-based cytology specimens; C-S, conventional specimens. ${ }^{*} p<0.05,{ }^{* * *} p<0.001$, vs. MALT-L; ${ }^{\dagger \dagger \dagger} p<0.001$ vs. C-S.

Table 2. Nuclear findings of lymphoid cells in thyroid lymphoma, Hashimoto thyroiditis with prominent lymphoid proliferation (HT-PTP), and papillary thyroid carcinoma with prominent lymphocytic infiltration (PTC-PLI) in liquid-based cytology specimens (LBC-S) and conventional specimens (C-S)

\begin{tabular}{|c|c|c|c|c|}
\hline & MALT-L (35) & DLBCL (3) & HT-PTP (25) & PTC-PLI (19) \\
\hline \multicolumn{5}{|c|}{ Nuclear size $($ mean \pm SD) } \\
\hline LBC-S & $7.7 \pm 1.22^{\dagger \dagger \dagger}$ & $8.6 \pm 2.43$ & $5.8 \pm 0.97^{\dagger \dagger \dagger, * * *}$ & $5.6 \pm 1.06^{\dagger \dagger, * * *}$ \\
\hline C-S & $5.5 \pm 0.59$ & $6.5 \pm 1.29 *$ & $5.1 \pm 0.43^{* *}$ & $4.8 \pm 0.30^{* * *}$ \\
\hline \multicolumn{5}{|c|}{ Large nuclei $(>10 \%,>10 \mu \mathrm{m})$} \\
\hline LBC-S & $62.9 \%(22)^{\dagger \dagger \dagger}$ & $100 \%(3)$ & $4.0 \%(1)^{* * *}$ & $5.3 \%(1)^{* * *}$ \\
\hline C-S & $0 \%(0)$ & $33.3 \%(1)$ & $0 \%(0)$ & $0 \%(0)$ \\
\hline \multicolumn{5}{|c|}{ Swollen naked nuclei } \\
\hline LBC-S & $91.4 \%(32)^{\dagger \dagger \dagger}$ & $100 \%(3)$ & $28.0 \%(7)^{\dagger, * * *}$ & $10.5 \%(2)^{* * *}$ \\
\hline C-S & $0 \%(0)$ & $0 \%(0)$ & $0 \%(0)$ & $0 \%(0)$ \\
\hline \multicolumn{5}{|c|}{ Elongated nuclei } \\
\hline LBC-S & $85.7 \%(30)^{\dagger \dagger \dagger}$ & $100 \%(3)$ & $20.0 \%(5)^{* * *}$ & $0 \%(0)^{* * *}$ \\
\hline C-S & $34.3 \%(12)$ & $33.3 \%(1)$ & $4.0 \%(1)^{* *}$ & $0 \%(0)^{* *}$ \\
\hline \multicolumn{5}{|c|}{ Cleaved nuclei } \\
\hline LBC-S & $68.6 \%(24)$ & $66.7 \%(2)$ & $20.0 \%(5)^{\dagger \dagger \dagger, * *}$ & $5.3 \%(1)^{* *}$ \\
\hline C-S & $85.7 \%(30)$ & $100 \%(3)$ & $84.0 \%(21)$ & $5.3 \%(1)^{* * *}$ \\
\hline
\end{tabular}

MALT-L, mucosa-associated lymphoid tissue lymphoma; DLBCL, diffuse large B-cell cell lymphoma. ${ }^{*} p<0.05,{ }^{* *} p<0.01,{ }^{* * *} p<0.001$, vs. MALT-L; ${ }^{\dagger} p<0.05,{ }^{\dagger \dagger} p<0.01,{ }^{\dagger \dagger \dagger} p<0.001$, vs. C-S.

MALT-L cases in conventional specimens, and the incidence was significantly lower than that in Hashimoto thyroiditis with prominent lymphoid proliferation $(76.0 \%$; $p<0.001)$. Comparison between LBC and conventional specimens of MALT-L revealed that there were fewer lymphoglandular bodies in LBC specimens than in conventional specimens $(p<0.001)$. In conventional specimens, most nonoxyphilic follicular cells appeared to have naked nuclei with a dense chromatin pattern and looked like lymphoid cells. In LBC specimens, they had a distinct cytoplasm, conspicuous nucleoli, and granular chromatin pattern, and could be easily identified (Fig. 1).

\section{Nuclear Findings}

The mean nuclear size in MALT-L was 7.7 and $5.5 \mu \mathrm{m}$ in LBC specimens and conventional specimens, respectively (Table 2). The nuclei in LBC specimens appeared significantly larger than those in conventional specimens $(p<0.001)$. The mean nuclear size of lymphocytes in Hashimoto thyroiditis with prominent lymphoid prolif- 


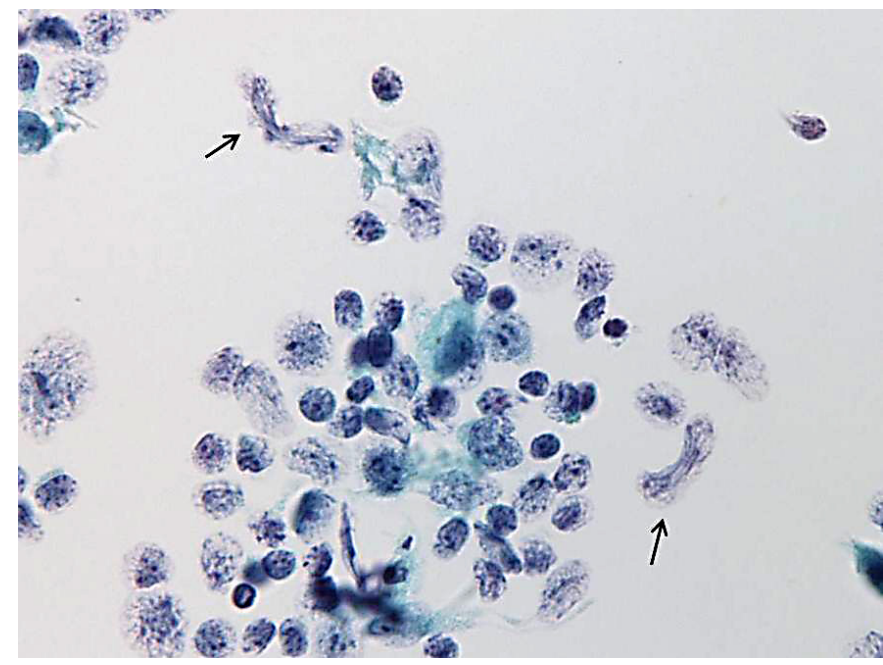

Fig. 2. Mucosa-associated lymphoid tissue lymphoma. Two elongated nuclei (arrows) with a major axis:minor axis ratio $>3$ are depicted (LBC). Papanicolaou stain. $\times 400$.

eration and PTC with prominent lymphocytic infiltration in LBC specimens was 5.8 and $5.6 \mu \mathrm{m}$, respectively, and the nuclei appeared significantly larger in LBC specimens than in conventional specimens $(p<0.001$ and $p<0.01$, respectively) and were significantly smaller than those in MALT-L $(p<0.001)$. In $62.9 \%$ of MALT-L and all DLBCL cases, large nuclei were present in $>10 \%$ of lymphoid cells in LBC specimens. One (4.0\%) case of Hashimoto thyroiditis with prominent lymphoid proliferation and 1 $(5.3 \%)$ case of PTC with prominent lymphocytic infiltration exhibited these findings. In conventional specimens, large nuclei (present in $>10 \%$ of lymphoid cells) were not observed in MALT-L, Hashimoto thyroiditis with prominent lymphoid proliferation, and PTC with prominent lymphocytic infiltration. Swollen naked nuclei (Fig. 1) were seen in $92.1 \%$ of lymphoma cases and $20.5 \%$ of benign lymphocyte cases in LBC specimens $(p<0.001)$. In conventional specimens, the findings were not seen in any of the lesions examined. In LBC specimens, elongated nuclei with a ratio of the major axis to the minor axis $>3$ (Fig. 2) and cleaved nuclei with a deep cleft in the nuclear margin (Fig. 3) were seen in 85.7 and $68.6 \%$ of MALT-L cases, and in all and $66.7 \%$ of DLBCL cases, respectively. Five (20.0\%) cases of Hashimoto thyroiditis with prominent lymphoid proliferation showed elongated and cleaved nuclei. No cases of PTC with prominent lymphocytic infiltration showed elongated nuclei. One (5.3\%) case with PTC with prominent lymphocytic infiltration showed cleaved nuclei.

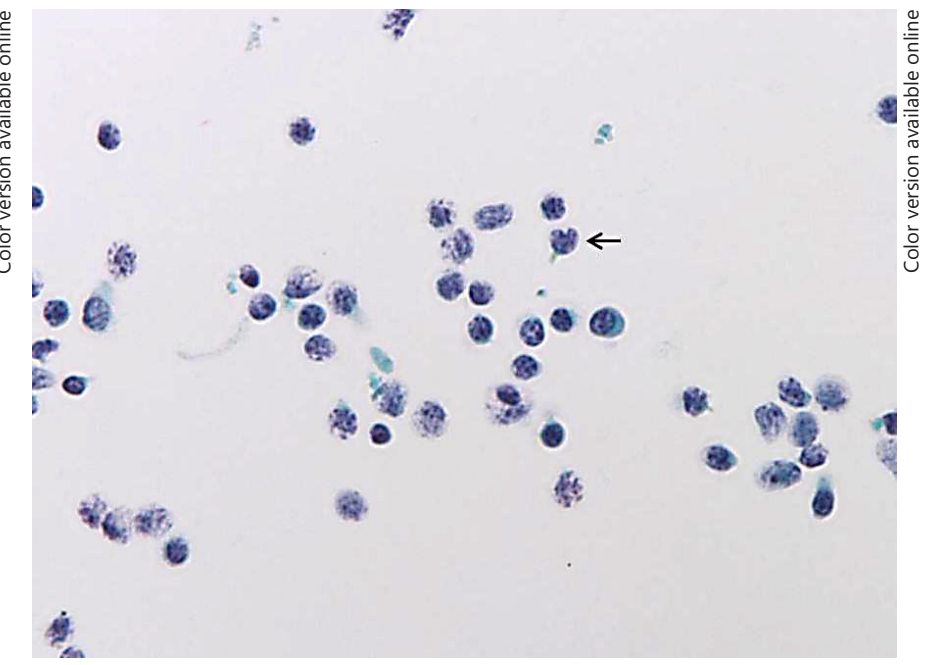

Fig. 3. Mucosa-associated lymphoid tissue lymphoma. Cleaved nuclei (arrow) with a deep cleft in the nuclear membrane are shown (LBC). Papanicolaou stain. $\times 400$.

\section{Discussion}

The most common subtype of primary thyroid lymphoma is DLBCL, followed by MALT-L [16]. According to Sangalli et al. [17], in cytological specimens, DLBCL shows a rich population of monotonous noncohesive, large-sized cells with moderate or abundant cytoplasm and prominent nucleoli. The diagnosis of lymphoma in DLBCL cases is not difficult. However, MALT-L shows a mixture of small- to medium-sized atypical lymphocytes, monocytoid B cells, immunoblasts, and plasma cells. Thus, it is frequently difficult to distinguish MALT-L from chronic thyroiditis [11-14]. All of these findings have only been observed for conventional specimens, and there are no reports describing the cytological findings of primary thyroid lymphoma using LBC specimens.

Ford et al. [18] described that lymphoid cells have a tendency to aggregate in LBC specimens and might be erroneously considered as follicular cells. However, in our study, follicular cells showed granular chromatin patterns and were quite different from lymphoid cells. This discrepancy may be due to the LBC methods used. They used the ThinPrep ${ }^{\circledR}$ method, but we used the CytoRich ${ }^{\mathrm{TM}}$ hand method. Therefore, we believe that LBC specimens are more useful for distinguishing between lymphoid and follicular cells.

Lymphoglandular bodies are cytoplasmic fragments and are a diagnostic clue for MALT-L [13]. In our study, they were more frequently seen in MALT-L than in 
Hashimoto thyroiditis with prominent lymphoid proliferation in conventional specimens. However, in LBC specimens, they were seen in only $11.4 \%$ of MALT-L cases. Therefore, we believe that lymphoglandular bodies are not reliable as indicators for lymphoma diagnosis in LBC specimens.

Oxyphilic cell clusters associated with abundant lymphocytes are clues for the diagnosis of chronic thyroiditis [12] and are not seen in primary thyroid lymphoma [19]. In our study, oxyphilic cell clusters were observed in 92.0\% of cases of Hashimoto thyroiditis with prominent lymphoid proliferation in LBC specimens. However, $42.9 \%$ of MALT-L specimens exhibited them. Thus, our results indicate that the presence of oxyphilic cell clusters cannot be used to rule out the possibility of MALT-L.

In previous reports, the nuclear and cytoplasmic sizes of follicular cells and well-differentiated thyroid carcinoma cells observed in LBC specimens were smaller than those in conventional specimens because the fixative used for LBC specimens contains formaldehyde $[2,3,5]$. In our study, the nuclear sizes in LBC specimens were larger than those in conventional specimens in both lymphoma cells and nonneoplastic lymphocytes. To the best of our knowledge, such findings have not been reported previously. Morphologically, the enlarged lymphoid cells in LBC specimens were degenerative and swollen. This phenomenon seems to be due to the fragility of the cells against the fixatives used in the LBC method. The findings were more remarkable in lymphoma cells than in nonneoplastic lymphocytes. Furthermore, in $62.9 \%$ of MALT-L and all DLBCL cases, large nuclei were present in $>10 \%$ of lymphoid cells in LBC specimens. Only 1 case of Hashimoto thyroiditis with prominent lymphoid proliferation and 1 case of PTC with prominent lymphocytic infiltration showed these findings. These results indicate that the large nuclei defined in this study might be an important finding indicating lymphoma in LBC specimens.

Moreover, the large nuclei were associated with degenerative changes. The nuclei were naked and exhibited less punctate chromatin patterns and thin nuclear margins. These swollen naked nuclei were noted in $92.1 \%$ of lymphoma cases and in $20.5 \%$ of nonlymphoma cases in LBC specimens. In conventional specimens, these findings were not observed in either lymphoma or nonlymphoma cases. Thus far, these findings have not been described in any study. In the CytoRich ${ }^{\mathrm{TM}}$ methodology, the aspirated cells are already fixed before centrifugation and smearing. Therefore, we believe that these nuclear alterations had already occurred at the time of fixation and are due to the effect of the fixative, CytoRich ${ }^{\mathrm{TM}}$ RED collection fluid.
Lymphoma cells seem to be more fragile than nonneoplastic lymphocytes when exposed to the fixative. We consider that the swollen naked nuclei are characteristic of LBC specimens and that their extensive appearance could be a novel indicator for a cytological diagnosis of lymphoma in LBC specimens using the CytoRich ${ }^{\mathrm{TM}}$ hand method.

Cleaved nuclei have been observed in lymphoma cells, particularly in B-cell lymphomas [20, 21]. We found that cleaved nuclei appeared significantly more often in lymphoma cells than in nonneoplastic lymphocytes, but the incidence in LBC specimens was lower than that in conventional specimens. We also found that elongated nuclei were significantly more apparent in primary thyroid lymphoma than in nonneoplastic lymphocytes, and that the incidence in LBC specimens was significantly higher than that in conventional specimens. Therefore, we consider that elongated nuclei are more useful than cleaved nuclei in distinguishing between primary thyroid lymphoma and nonneoplastic lymphocytes in LBC specimens.

In conclusion, our findings indicate that large nuclei with a major axis of $>10 \mu \mathrm{m}$ present in $>10 \%$ of lymphoid cells, elongated nuclei, and markedly swollen naked nuclei are important clues for distinguishing thyroid primary lymphoma from nonneoplastic lymphocytes on LBC specimens. Furthermore, we also showed that LBC specimens help to distinguish between lymphoid and follicular cells. Lymphoglandular bodies are not reliable indicators for making decisions on lymphoma diagnosis using LBC specimens. However, if methods other than the CytoRich $^{\mathrm{TM}}$ hand method are used, the findings may be different; this aspect needs to be addressed in the future.

\section{Acknowledgment}

We would like to thank Editage (www.editage.jp) for English language editing.

\section{Statement of Ethics}

Our study conforms to the guidelines of the Ethics Committee of the Kuma Hospital, and all subjects gave informed consent.

\section{Disclosure Statement}

There are no conflicts of interest to declare. 


\section{References}

1 Rossi ED, Morassi F, Santeusanio G, Zannoni GF, Fadda G: Thyroid fine needle aspiration cytology processed by ThinPrep: an additional slide decreased the number of inadequate results. Cytopathology 2010;21:97-102.

2 Suzuki A, Hirokawa M, Higuchi M, Yamao N, Kuma S, Nakamura H, Amino N, Miyauchi A: Cytological characteristics of papillary thyroid carcinoma on LBC specimens, compared with conventional specimens. Diagn Cytopathol 2015;43:108-113.

3 Suzuki A, Hirokawa M, Higuchi M, Takada N, Yamao N, Kuma S, Miyauchi A: Differentiating between benign follicular nodules and follicular neoplasms in thyroid liquid-based cytology preparations. Diagn Cytopathol 2016;44:659-664.

4 Fischer AH, Clayton AC, Bentz JS, Wasserman PG, Henry MR, Souers RJ, Moriarty AT: Performance differences between conventional smears and liquid-based preparations of thyroid fine-needle aspiration samples. Arch Pathol Lab Med 2013;137:26-31.

5 Mygdakos N, Nikolaidou S, Tzilivaki A, Tamiolakis D: Liquid based preparation (LBP) cytology versus conventional cytology (CS) in FNA samples from breast, thyroid, salivary glands and soft tissues. Our experience in Crete (Greece). Rom J Morphol Embryol 2009;50:245-250.

6 Jung CK, Lee A, Jung ES, Choi YJ, Jung SL, Lee KY: Split sample comparison of a liquidbased method and conventional smears in thyroid fine needle aspiration. Acta Cytol 2008;52:313-319.
7 Aozasa K: Hashimoto's thyroiditis as a risk factor of thyroid lymphoma of the thyroid gland. Acta Pathol Jpn 1990;40:459-468.

8 Kato I, Tajima K, Suchi T, Aozasa K, Matsuzuka F, Kuma K, Tominaga S: Chronic thyroiditis as a risk factor of B-cell lymphoma in the thyroid gland. Jpn J Cancer Res 1985;76: 1085-1090.

9 Alzouebi M, Goepel JR, Horsman JM, Hancock BW: Primary thyroid lymphoma: the 40 year experience of a UK lymphoma treatment centre. Int J Oncol 2012;40:2075-2080.

10 Stein SA, Wartofsky L: Primary thyroid lymphoma: a clinical review. J Clin Endocrinol Metab 2013;98:3131-3138.

11 Layfield LJ, Waisman J, Atkins KA: Metastatic tumors and lymphomas; in Ali SZ, Cibas ES (ed): The Bethesda System for Reporting Thyroid Cytopathology: Definitions, Criteria and Explanatory Notes. New York, Springer, 2010, p 162.

12 DeMay RM: 12: thyroid; in DeMay RM (ed): The Art \& Science of Cytopathology, ed 2. Hong Kong, ASCP Press, 2012, vol 2: Superficial Aspiration Cytology, p 929.

13 Abraham LK, Matthai A, Thomas S, Joseph E: Fine needle aspiration cytology of primary thyroid lymphoma. Int Surg J 2014;1:53-55.

14 Hirokawa M, Suzuki A: MALT lymphoma vs. Hashimoto thyroiditis; in Kakudo K (ed): Thyroid FNA Cytology Differential Diagnoses and Pitfall. Himeji, BookWay, 2016, pp 125-131.

15 Hirokawa M, Kudo T, Ota H, Suzuki A, Kobayashi K, Miyauchi A: Preoperative diagnostic algorithm of primary thyroid lymphoma using ultrasound, aspiration cytology, and flow cytometry. Endocr J 2017;64:859-865.
16 Walsh S, Lowery AJ, Evoy D, McDermott EW, Prichard RS: Thyroid lymphoma: recent advances in diagnosis and optimal management strategies. Oncologist 2013;18:9941003.

17 Sangalli G, Serio G, Zampatti C, Lomuscio G, Colombo L: Fine needle aspiration cytology of primary lymphoma of the thyroid: a report of 17 cases. Cytopathology 2001;12:257-263.

18 Ford L, Rasgon BM, Hilsinger RL Jr, Cruz RM, Axelsson K, Rumore GJ, Schmidtknecht TM, Puligandla B, Sawicki J, Pshea W: Comparison of ThinPrep versus conventional smear cytopreparatory techniques for fineneedle aspiration specimens of head and neck masses. Otolaryngol Head Neck Surg 2002; 126:554-561.

19 Thompson LDR: Primary thyroid lymphomas; in Nikiforov YE, Biddinger PW, Thompson LDR (eds): Diagnostic Pathology and Molecular Genetics of the Thyroid. Baltimore, Lippincott Williams \& Wilkins, 2009, pp 333-347.

20 Gatter KC, Warnke RA: Diffuse large B-cell lymphoma; in Jaffe ES, Harris NL, Stein H, Vardiman JW (eds): World Health Organization Classification of Tumours: Pathology and Genetics of Tumours of Haematopoietic and Lymphoid Tissues. Lyon, IARC Press, 2001, p 171.

21 Chan JK: Tumors of the lymphoreticular system; in Fletcher CDM (ed): Diagnostic Histopathology of Tumors, ed 3. Philadelphia, Churchill Livingstone Elsevier, 2007, vol 2, pp 1197-1201. 